\title{
An Exploration of Link Functions Used in Ordinal Regression
}

Thomas J. Smith

Northern Illinois University, tjsmith@niu.edu

David A. Walker

Northern Illinois University, dawalker@niu.edu

Cornelius M. McKenna

Independent Scholar, Chana, IL, nmckenna78@gmail.com

Follow this and additional works at: https://digitalcommons.wayne.edu/jmasm

Part of the Applied Statistics Commons, Social and Behavioral Sciences Commons, and the Statistical Theory Commons

\section{Recommended Citation}

Smith, T. J., Walker, D. A., \& McKenna, C. M. (2019). An exploration of link functions used in ordinal regression. Journal of Modern Applied Statistical Methods, 18(1), eP2905. doi: 10.22237/jmasm/ 1556669640

This Regular Article is brought to you for free and open access by the Open Access Journals at DigitalCommons@WayneState. It has been accepted for inclusion in Journal of Modern Applied Statistical Methods by an authorized editor of DigitalCommons@WayneState. 


\section{An Exploration of Link Functions Used in Ordinal Regression}

\author{
Thomas J. Smith \\ Northern Illinois University \\ DeKalb, IL
}

\author{
David A. Walker \\ Northern Illinois University \\ DeKalb, IL
}

\author{
Cornelius M. McKenna \\ Independent Scholar \\ Chana, IL
}

The purpose of this study is to examine issues involved with choice of a link function in generalized linear models with ordinal outcomes, including distributional appropriateness, link specificity, and palindromic invariance are discussed and an exemplar analysis provided using the Pew Research Center 25th anniversary of the Web Omnibus Survey data. Simulated data are used to compare the relative palindromic invariance of four distinct indices of determination/discrimination, including a newly proposed index by Smith et al. (2017).

Keywords: $\quad$ Ordinal, regression, link, functions

\section{Introduction}

Ordinal regression models provide an appropriate strategy for educational researchers when predicting an ordered, observed categorical outcome. These regression models fall within a class of regression models known as generalized linear models, in the sense that they allow for a more generalized distribution of error terms - i.e., one that differs from the normal distribution of errors prescribed by ordinal least squares (OLS) regression. When fitting generalized linear models to ordinal response outcomes, the researcher has recourse to a number of distinct "link functions" that that are used to link the (cumulative) response to the set of predictor variables. For example, a logit link function,

$$
\mathrm{g}(u)=\ln \left(\frac{u}{1-u}\right)
$$

doi: 10.22237/jmasm/1556669640 | Accepted: September 16, 2018; Published: April 20, 2020.

Correspondence: David A. Walker, dawalker@niu.edu 


\section{SMITH ET AL}

may be chosen, where $u$ is the cumulative probability of a particular outcome. The logit link function is the most commonly-employed - and typically the defaultlink function employed when fitting ordinal regression models and allows for the effects associated with specific predictor variables to be expressed as odds-ratios. Other, alternative link functions used with ordinal regression models include the complementary log-log link function,

$$
\mathrm{g}(u)=\ln (-\ln (1-u))
$$

the negative log-log link function,

$$
\mathrm{g}(u)=-\ln (-\ln (u))
$$

the Cauchit link function,

$$
\mathrm{g}(u)=\tan (\pi(u-0.5))
$$

and the probit link function,

$$
\mathrm{g}(u)=\Phi^{-1}(u)
$$

where $\Phi$ is the cumulative normal distribution function.

There is some variability in the literature regarding recommendations for choosing a particular link function for an ordinal regression analysis. Norusis (2012) suggests the choice link function should be based on the distribution of the response variable. Specifically, she recommends use of the logit link function for uniformly distributed ordinal outcomes; the complementary log-log and negative $\log$-log link function for negatively-skewed and positively-skewed outcomes, respectively; the Cauchit link function for distributions with many extreme values; and the probit link function for outcomes with a latent, underlying normal distribution. Hilbe (2009) indicates that, at least for logit models, the appropriateness of the logit link specification should be tested by assessing the relationship between the logit and any continuous predictors for linearity. One method for assessing this is the Box-Tidwell test (Box \& Tidwell, 1962), in which an interaction term consisting of the products of any continuous predictors and their log-transformed values is used in combination with the regressors of interest to 


\section{AN EXPLORATION OF LINK FUNCTIONS}

predict the outcome, and statistical significance of this interaction term indicates

potential violation of linearity.

Pregibon (1980) provides a two-parameter generalization of the logit link function,

$$
\mathrm{g}(u, a, b)=\frac{u^{a-b}-1}{a-b}-\frac{(1-u)^{a+b}-1}{a+b}
$$

where $\mathrm{a}$ and $\mathrm{b}$ are parameters used to control for kurtosis and skewness, respectively, of the transformed outcome. When $a$ and $b$ in Pregibon's function approach zero, it reduces to the logit link function; i.e.:

$$
\begin{aligned}
\lim _{(a, b) \rightarrow(0,0)}\left(\frac{u^{a-b}-1}{a-b}-\frac{(1-u)^{a+b}-1}{a+b}\right) & =\lim _{a \rightarrow 0}\left(\lim _{b \rightarrow 0}\left[\frac{u^{a-b}-1}{a-b}-\frac{(1-u)^{a+b}-1}{a+b}\right]\right) \\
& =\lim _{a \rightarrow 0}\left(\frac{u^{a}-1}{a}-\frac{(1-u)^{a}-1}{a}\right) \\
& =\lim _{a \rightarrow 0} \frac{u^{a}-(1-u)^{a}}{a}, \\
& \operatorname{and} \operatorname{applying~L'Hôpital's~Rule,~} \\
& \lim _{a \rightarrow 0} \frac{u^{a} \ln (u)-(1-u)^{a} \ln (1-u)}{1} \\
& =\ln (u)-\ln (1-u) \\
& =\ln \left(\frac{u}{1-u}\right)
\end{aligned}
$$

Similarly, the Student's $t$ link function can be considered a generalized link function, where the shape of the cumulative probability distribution varies by the degrees of freedom parameter (see Koenker, 2006). Here, $d f=1$ results in the Cauchit link function, while $d f=\infty$ results in the probit link function. Koenker further details how regression results obtained with specific choices of parameter choices $a, b$, or $d f$ in these parametric link functions can be compared to results obtained using traditional Cauchit or logit models. Cole and McDonald (1989) propose a goodness-of-link bootstrapping test, but this is outlined for binary outcomes only. Others (e.g., Johnson \& Albert, 1999) suggest that the link function 


\section{SMITH ET AL}

might be chosen to address over-dispersion in the outcome - defined as situations in which the value of the model deviance divided by the model degrees of freedom exceeds unity.

An additional issue that arises in ordinal regression models concerns the symmetry of the link function. A link function is considered "symmetric" if the latent likelihood of a particular response outcome approaches zero at the same rate that it approaches unity, whereas this is not the case for link functions that are asymmetric. Examples of the former include the logit, Cauchit, and probit functions, while examples of the latter include the complementary log-log and negative log$\log$ functions. One anomaly that can occur when an asymmetric link function is used in ordinal regression concerns the estimated model parameters and indices of model fit - including coefficients of determination/discrimination (i.e., "pseudo $R^{2}$ " values)—whereby these estimates can depend upon the "direction" of the coding for the outcome variable. That is, for example, the regression of an ordinal outcome coded as $1=$ strongly disagree, $2=$ disagree, 3 = agree, and $4=$ strongly agree on a set of predictors can lead to distinct set of estimates from those resulting from same regression, but where the outcome is coded as $1=$ strongly agree, $2=$ agree, $3=$ disagree , and $4=$ strongly disagree . McCullagh $(1978,1980)$ suggests that a desirable property of regression estimates is the extent to which they exhibit "palindromic invariance"-that is, invariance to such coding reversals. One class of parameter estimates that would ideally show palindromic invariance are "pseudo $R^{2}$ " indices, which are statistics intended to serve as analogs to the more wellknown $R^{2}$ indices encountered in ordinary least-squares (OLS) regression. Wellknown and frequently-used pseudo $R^{2}$ indices include those proposed by McFadden (1974), Cox and Snell (1989), and Nagelkerke (1991). Smith et al. (2017) proposed a new coefficient of discrimination $\left(D^{\prime}\right)$ for ordinal and nominal regression models that is a generalization of the coefficient proposed by Tjur (2009). This $D^{\prime}$ coefficient reflects the average difference in predicted probabilities between each outcome category and its complement,

$$
D^{\prime}=\frac{\sum_{i=1}^{K}\left|\overline{\hat{\pi}}_{1 i}-\overline{\hat{\pi}}_{0 i}\right|}{K},
$$

where $\overline{\hat{\pi}}_{1 i}$ and $\overline{\hat{\pi}}_{0 i}$ refer to the mean predicted probability of being in category $i$ for cases corresponding to response category " $i$ " and "not $i$," respectively; and where $K$ denotes the total number of outcome categories (or, equivalently, the number of sets of predicted probabilities). The present study seeks to compare the palindromic 


\section{AN EXPLORATION OF LINK FUNCTIONS}

invariance of $D^{\prime}$ to three extant coefficients of discrimination (i.e., "pseudo $R^{2}$ indices")—-specifically, those proposed by McFadden, Cox and Snell, and Nagelkerke.

\section{Method}

Ordinal regression models are fitted to data obtained from the Pew Research Center's (2014) 25th anniversary of the Web Omnibus Survey data. The Pew data contained survey responses to internet- and technology-related queries from $N=1006$ adults ranging from 18 to 93 years of age. Specifically, we considered six ordinal outcomes pertaining to individuals' perceptions of how difficult it would be to give up various technological aspects of their lives (i.e., television, landline phone, cell phone or smartphone, the Internet, email, and social media such as Facebook and Twitter). Response options included $1=$ very hard, $2=$ somewhat hard, $3=$ not too hard, and $4=$ not hard at all. Two predictors were used in the ordinal regression models: (1) gender (coded as $0=$ male and $1=$ female), and (2) age in years. We first evaluated skewness in the outcomes and, based on the type of skewness, fitted the ordinal regression models using the appropriate link functions suggested by Norusis (2012), and compared these results to the same regression models fitted using the more conventional logit link function. Additionally, we computed several coefficients of determination: McFadden's (1974) $R^{2}$, Cox and Snell's (1989) $R^{2}$, and Nagelkerke's (1991) $R^{2}$, as well as the $D^{\prime}$ coefficient of discrimination developed by Smith et al. (2017). We evaluated potential over-dispersion by computing, for each model, the ratio of the deviance to the degrees of freedom for the model.

Additionally, ordinal regression models are fitted to simulated regression data, generated using $\mathrm{R}$ statistical software. The simulated regression data consisted of randomly-generated unit normal covariates specified to predict a five-category ordinal outcome. Distinct sets of randomly-generated samples were generated, differing by (1) degree and direction of skewness (see Figure 1 for skewness conditions), (2) correlation among the covariates, and (3) sample size. Ordinal regression models were fitted to these data using both symmetric (logit) and asymmetric (complementary log-log) link functions and employing both the original coding of the dependent variable (1 through 5) as well as a reverse-coding (5 through 1). Ten thousand Monte Carlo sample replications were carried out for each experimental condition, with distinct random seeds used for each experimental condition. 


\section{SMITH ET AL}
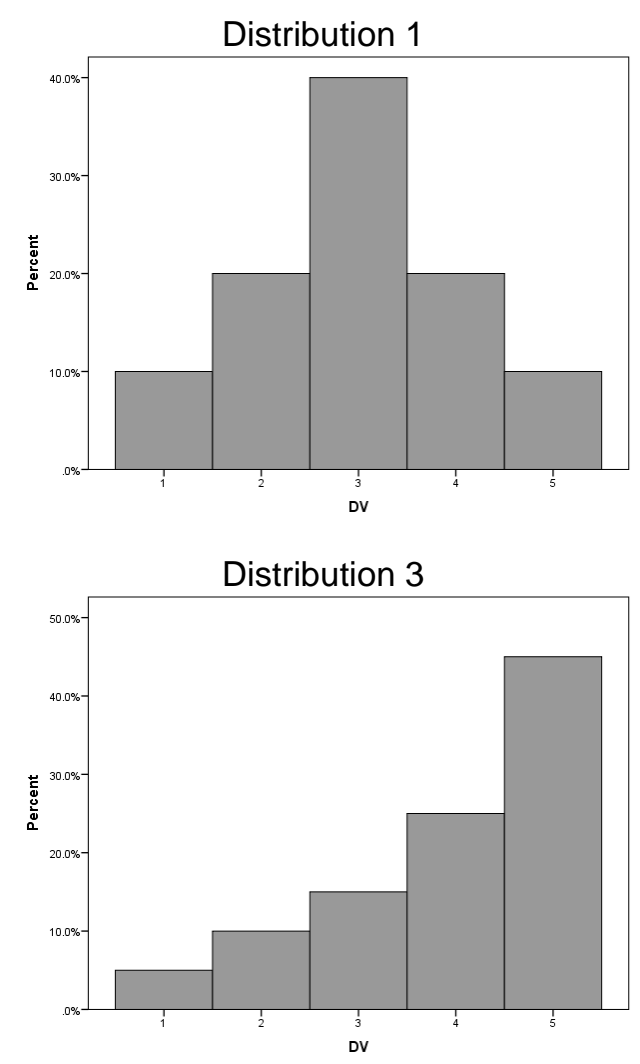

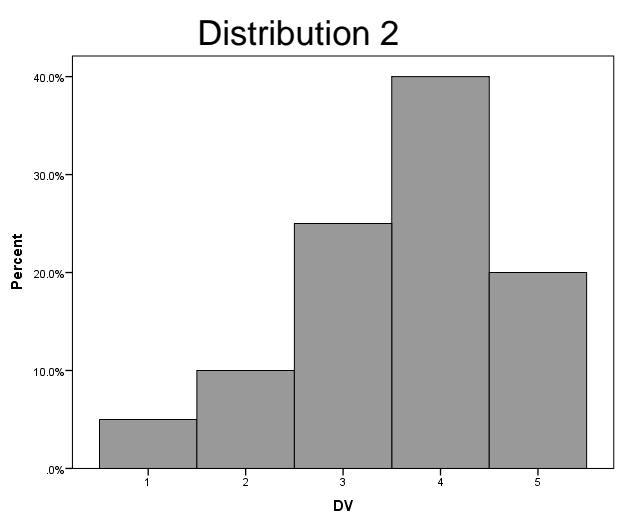

Distribution 4

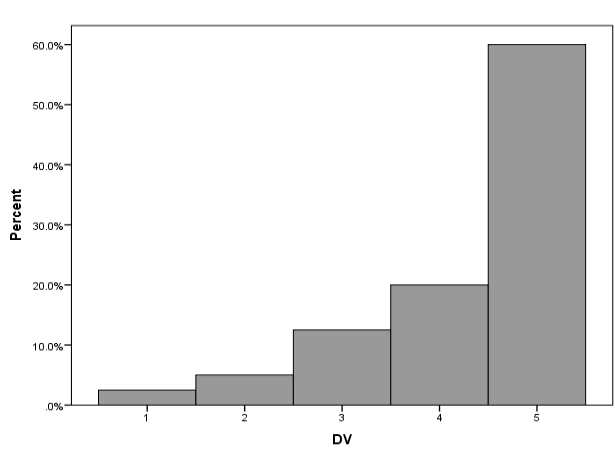

Figure 1. Distribution conditions 1, 2, 3, and 4 for outcome variables in simulated regression data

\section{Results}

Using the Pew Research Center (2014) data, first consider the distributional characteristics of the six ordinal outcomes (Table 1). Several of the outcomes included a large number of missing values. This was to be expected, however, because some of the queries did not apply to all persons (e.g., persons with no landline telephone). Each of the six outcomes showed some degree of nonuniformity in distribution, with perceived difficulty of giving up a cell phone or smartphone, the Internet, and social media exhibiting the strongest skewness. For these most strongly skewed outcomes, the recommendations of Norusis (2012) would suggest a complementary log-log link function for the outcome of "social media" due to strong negative skewness, and a negative log-log link for the 


\section{AN EXPLORATION OF LINK FUNCTIONS}

outcomes of "cell phone or smartphone," and "the Internet" due to strong positive skewness.

Shown in Tables 2 and 3 are the results of ordinal regression models fitted to the outcomes, using either a logit link function, or an appropriate link function (negative log-log or complementary log-log) as per Norusis' recommendations. All models showed good fit, with non-significant Pearson and deviance $X^{2}$ statistics, and significant reductions in the $-2 \log$ likelihood values. Using an a priori $\alpha=.05$ criterion for statistical significance, the choice of link function did not alter any decisions about the statistical significance of individual predictors. However, when using a stricter $\alpha=.01$ criterion level, the choice of link function did change inferences about the statistical significance of one predictor (sex) for one outcome ("giving up a cell phone or smartphone"). Table 4 provides over-dispersion values for each of the fitted models. Five of the six models (all except the model predicting "giving up landline telephone") exhibited some degree of over-dispersion.

Next, the Box-Tidwell test of linearity was conducted to assess the linear relationship between the continuous predictor (age) and the logit. Here, statistical significance of the age $\times \ln$ (age) regression term included in the ordinal regression model would indicate non-linearity between the logit and the predictor (i.e., misspecification of the link function). Interestingly, when the Box-Tidwell test was applied to each ordinal regression model to assess the appropriateness of the logit link specification, misspecification of the link was indicated solely for the outcome of "giving up a television" ( $p=.004)$, although several other outcomes showed even more extreme skewness than this variable (Table 1). Clearly, with these data, the extent of skewness was not necessarily related to potential violations of linearity between continuous predictors and the logit.

Table 1. Frequency of respondents indicating difficulty in giving up technology-related aspects of their lives $(N=1006)$

\begin{tabular}{|c|c|c|c|c|c|c|}
\hline \multirow[b]{2}{*}{$\begin{array}{r}\text { Degree of } \\
\text { difficulty }\end{array}$} & \multicolumn{6}{|c|}{$\begin{array}{c}\text { How difficult would it be, if at all, to give up the following things in your life? } \\
\text { How hard would it be for you to give up... }\end{array}$} \\
\hline & $\begin{array}{r}\text { your } \\
\text { television? }\end{array}$ & $\begin{array}{r}\text { your landline } \\
\text { telephone? }\end{array}$ & $\begin{array}{l}\text { your cell phone } \\
\text { or smartphone? }\end{array}$ & $\begin{array}{r}\text { the } \\
\text { Internet? }\end{array}$ & email? & $\begin{array}{l}\text { social media such as } \\
\text { Facebook or Twitter? }\end{array}$ \\
\hline $1=$ Very hard & 342 & 167 & 435 & 455 & 312 & 97 \\
\hline $\begin{array}{r}2=\text { Somewhat } \\
\text { hard }\end{array}$ & 228 & 115 & 193 & 172 & 181 & 149 \\
\hline $\begin{array}{r}3=\text { Not too } \\
\text { hard }\end{array}$ & 214 & 132 & 145 & 130 & 173 & 186 \\
\hline $\begin{array}{r}4=\text { Not hard } \\
\text { at all }\end{array}$ & 205 & 172 & 121 & 101 & 183 & 351 \\
\hline $\begin{array}{r}\text { Missing/Not- } \\
\text { applicable }\end{array}$ & 17 & 420 & 112 & 148 & 158 & 223 \\
\hline
\end{tabular}

Note: Cases have been weighted by provided sampling weights 


\section{SMITH ET AL}

Table 2. Results for regression of ordinal outcomes on sex and age (positively-skewed outcomes only)

\begin{tabular}{|c|c|c|c|c|c|c|c|c|c|c|c|}
\hline \multirow[b]{2}{*}{ Outcome } & \multirow[b]{2}{*}{ Effect } & \multicolumn{5}{|c|}{ Logit link function } & \multicolumn{5}{|c|}{ Negative log-log link function } \\
\hline & & $\boldsymbol{b}$ & SE & Wald & $d f$ & $p$ & $b$ & SE & Wald & $d f$ & $p$ \\
\hline \multirow[t]{5}{*}{ Television } & Threshold 1 & -2.284 & 0.191 & 142.818 & 1 & $<.001$ & -1.244 & 0.119 & 108.751 & 1 & $<.001$ \\
\hline & Threshold 2 & -1.242 & 0.180 & 47.332 & 1 & $<.001$ & -0.533 & 0.118 & 20.456 & 1 & $<.001$ \\
\hline & Threshold 3 & -0.143 & 0.178 & 0.647 & 1 & 0.421 & 0.357 & 0.126 & 8.081 & 1 & 0.004 \\
\hline & Age & -0.035 & 0.003 & 100.684 & 1 & $<.001$ & -0.025 & 0.002 & 111.880 & 1 & $<.001$ \\
\hline & Sex (male) & -0.006 & 0.118 & 0.002 & 1 & 0.962 & -0.018 & 0.080 & 0.049 & 1 & 0.825 \\
\hline \multirow[t]{5}{*}{ Cell phone or smartphone } & Threshold 1 & 0.534 & 0.190 & 7.865 & 1 & 0.005 & 0.697 & 0.144 & 23.266 & 1 & $<.001$ \\
\hline & Threshold 2 & 1.451 & 0.196 & 54.827 & 1 & $<.001$ & 1.408 & 0.151 & 87.232 & 1 & $<.001$ \\
\hline & Threshold 3 & 2.443 & 0.209 & 136.880 & 1 & $<.001$ & 2.284 & 0.165 & 190.635 & 1 & $<.001$ \\
\hline & Age & 0.009 & 0.004 & 6.270 & 1 & 0.012 & 0.006 & 0.003 & 4.067 & 1 & 0.044 \\
\hline & Sex (male) & 0.360 & 0.126 & 8.119 & 1 & 0.004 & 0.234 & 0.095 & 6.052 & 1 & 0.014 \\
\hline \multirow[t]{5}{*}{ The Internet } & Threshold 1 & 0.743 & 0.198 & 14.053 & 1 & $<.001$ & 0.915 & 0.155 & 35.038 & 1 & $<.001$ \\
\hline & Threshold 2 & 1.640 & 0.205 & 64.015 & 1 & $<.001$ & 1.630 & 0.162 & 101.508 & 1 & $<.001$ \\
\hline & Threshold 3 & 2.661 & 0.220 & 145.849 & 1 & $<.001$ & 2.547 & 0.179 & 202.116 & 1 & $<.001$ \\
\hline & Age & 0.009 & 0.004 & 5.890 & 1 & 0.015 & 0.007 & 0.003 & 5.622 & 1 & 0.018 \\
\hline & Sex (male) & 0.425 & 0.132 & 10.392 & 1 & 0.001 & 0.295 & 0.102 & 8.438 & 1 & 0.004 \\
\hline \multirow[t]{5}{*}{ Email } & Threshold 1 & -0.456 & 0.188 & 5.877 & 1 & 0.015 & 0.069 & 0.131 & 0.283 & 1 & 0.595 \\
\hline & Threshold 2 & 0.418 & 0.188 & 4.931 & 1 & 0.026 & 0.682 & 0.134 & 25.839 & 1 & $<.001$ \\
\hline & Threshold 3 & 1.403 & 0.194 & 52.085 & 1 & $<.001$ & 1.501 & 0.144 & 108.460 & 1 & $<.001$ \\
\hline & Age & -0.002 & 0.004 & 0.275 & 1 & 0.600 & -0.001 & 0.003 & 0.144 & 1 & 0.704 \\
\hline & Sex (male) & 0.357 & 0.126 & 8.057 & 1 & 0.005 & 0.230 & 0.088 & 6.842 & 1 & 0.009 \\
\hline
\end{tabular}




\section{AN EXPLORATION OF LINK FUNCTIONS}

Table 3. Results for regression of ordinal outcomes on sex and age (negatively-skewed outcomes only)

\begin{tabular}{|c|c|c|c|c|c|c|c|c|c|c|c|}
\hline \multirow[b]{2}{*}{ Outcome } & \multirow[b]{2}{*}{ Effect } & \multicolumn{5}{|c|}{ Logit link function } & \multicolumn{5}{|c|}{ Negative log-log link function } \\
\hline & & $\boldsymbol{b}$ & SE & Wald & df & $p$ & $\boldsymbol{b}$ & SE & Wald & df & $r$ \\
\hline \multirow[t]{5}{*}{ Landline telephone } & Threshold 1 & -2.726 & 0.282 & 93.223 & 1 & $<.001$ & -2.229 & 0.198 & 127.112 & 1 & $<.001$ \\
\hline & Threshold 2 & -1.767 & 0.269 & 43.042 & 1 & $<.001$ & -1.515 & 0.188 & 64.751 & 1 & $<.001$ \\
\hline & Threshold 3 & -0.731 & 0.261 & 7.837 & 1 & 0.005 & -0.862 & 0.180 & 22.828 & 1 & $<.001$ \\
\hline & Age & -0.038 & 0.005 & 65.737 & 1 & $<.001$ & -0.024 & 0.003 & 61.700 & 1 & $<.001$ \\
\hline & Sex (male) & 0.630 & 0.157 & 16.036 & 1 & $<.001$ & 0.376 & 0.105 & 12.898 & 1 & $<.001$ \\
\hline \multirow[t]{5}{*}{ Social media } & Threshold 1 & -1.001 & 0.206 & 23.687 & 1 & $<.001$ & -1.273 & 0.162 & 62.072 & 1 & $<.001$ \\
\hline & Threshold 2 & 0.201 & 0.196 & 1.044 & 1 & 0.307 & -0.214 & 0.142 & 2.250 & 1 & 0.134 \\
\hline & Threshold 3 & 1.232 & 0.201 & 37.511 & 1 & $<.001$ & 0.563 & 0.139 & 16.344 & 1 & $<.001$ \\
\hline & Age & 0.018 & 0.004 & 20.360 & 1 & $<.001$ & 0.014 & 0.003 & 22.388 & 1 & $<.001$ \\
\hline & Sex (male) & 0.442 & 0.135 & 10.772 & 1 & 0.001 & 0.340 & 0.099 & 11.939 & 1 & 0.001 \\
\hline
\end{tabular}

Table 4. Over-dispersion for regression of ordinal outcomes on sex and age

\begin{tabular}{rr} 
Outcome & Over-dispersion (Deviance/df) \\
\hline Television & 1.22 \\
Landline phone & 0.97 \\
Cell phone of smartphone & 1.15 \\
The Internet & 1.08 \\
Email & 1.15 \\
Social media & 1.04 \\
\hline
\end{tabular}




\section{SMITH ET AL}

Table 5. Values for coefficients of determination and discrimination resulting from ordinal regression of ordinal outcomes on sex and age using a complementary log-log link function and either (1) original coding or (2) reverse coding of outcome

\begin{tabular}{|c|c|c|c|c|}
\hline Outcome & Coefficient & Original coding & Reverse-coding & |Difference| \\
\hline \multirow[t]{4}{*}{ Television } & $R_{\mathrm{M}}^{2}$ & 0.031 & 0.043 & 0.012 \\
\hline & $R_{\mathrm{CS}}^{2}$ & 0.082 & 0.110 & 0.028 \\
\hline & $R_{N}^{2}$ & 0.087 & 0.118 & 0.031 \\
\hline & $D^{\prime}$ & 0.030 & 0.037 & 0.007 \\
\hline \multirow[t]{4}{*}{ Telephone landline } & $R_{\mathrm{M}}^{2}$ & 0.051 & 0.057 & 0.006 \\
\hline & $R_{\mathrm{CS}}^{2}$ & 0.131 & 0.144 & 0.013 \\
\hline & $R_{\mathrm{N}}^{2}$ & 0.140 & 0.154 & 0.014 \\
\hline & $D^{\prime}$ & 0.050 & 0.049 & 0.001 \\
\hline \multirow[t]{4}{*}{ Cell phone or smartphone } & $R_{\mathrm{M}}^{2}$ & 0.009 & 0.005 & 0.004 \\
\hline & $R_{\mathrm{CS}}^{2}$ & 0.022 & 0.011 & 0.011 \\
\hline & $R_{\mathrm{N}}^{2}$ & 0.024 & 0.012 & 0.012 \\
\hline & $D^{\prime}$ & 0.006 & 0.003 & 0.003 \\
\hline \multirow[t]{4}{*}{ The Internet } & $R_{\mathrm{M}}^{2}$ & 0.009 & 0.007 & 0.002 \\
\hline & $R_{\mathrm{CS}}^{2}$ & 0.022 & 0.019 & 0.003 \\
\hline & $R_{N}^{2}$ & 0.024 & 0.017 & 0.007 \\
\hline & $D^{\prime}$ & 0.004 & 0.004 & 0.000 \\
\hline \multirow[t]{4}{*}{ Email } & $R_{\mathrm{M}}^{2}$ & 0.004 & 0.003 & 0.001 \\
\hline & $R_{\mathrm{CS}}^{2}$ & 0.010 & 0.008 & 0.002 \\
\hline & $R_{\mathrm{N}}^{2}$ & 0.011 & 0.009 & 0.002 \\
\hline & $D^{\prime}$ & 0.009 & 0.008 & 0.001 \\
\hline \multirow[t]{4}{*}{ Social media } & $R_{\mathrm{M}}^{2}$ & 0.018 & 0.012 & 0.006 \\
\hline & $R_{\mathrm{CS}}^{2}$ & 0.044 & 0.029 & 0.015 \\
\hline & $R_{\mathrm{N}}^{2}$ & 0.048 & 0.031 & 0.017 \\
\hline & $D^{\prime}$ & 0.013 & 0.010 & 0.003 \\
\hline
\end{tabular}

Note: $\quad R_{\mathrm{M}}^{2}$ is McFadden's (1974) coefficient, $R_{\mathrm{cS}}^{2}$ is Cox and Snell's (1989) coefficient, $R_{\mathrm{N}}^{2}$ is Nagelkerke's (1991) coefficient; the $D^{\prime}$ coefficient was developed by Smith et al. (2017); the difference between estimated values of the coefficients provides an indication of palindromic invariance, with small differences indicative of greater invariance 


\section{AN EXPLORATION OF LINK FUNCTIONS}

Shown in Table 5 are the values for three distinct coefficients of determination fitted to the Pew data-McFadden's (1974) $R^{2}$, Cox and Snell's (1989) $R^{2}$, and Nagelkerke's (1991) $R^{2}$, as well as the $D^{\prime}$ coefficient of discrimination developed by Smith et al. (2017), computed for each of the ordinal outcomes, and using an asymmetric (complementary log-log) link function for both the originally-coded outcome $(1=$ very hard, $2=$ somewhat hard, $3=$ not too hard, and $4=$ not hard at all $)$ and the reverse-coded outcome $(1=$ not hard at all, $2=$ not hard, $3=$ somewhat hard, and $4=$ very hard). As can be seen in Table 4 , strong palindromic invariance was evident among these indices. That is, the values of these pseudo $R^{2}$ values changed very little from the original coding to the reverse coding. However, for each outcome, the $D^{\prime}$ coefficient of discrimination showed the greatest palindromic invariance, as evidenced by the smallest difference between computed $D^{\prime}$ values for the original-coding and reverse-coding of the outcomes.

Table 6. Mean (and standard deviation) values of coefficients of determination/ discrimination resulting from ordinal regression models fitted to a randomly-simulated data under three coding/link function conditions $(N=500)$

\begin{tabular}{crrrrr} 
Coefficient & $\begin{array}{r}\text { Distribution } \\
\text { of outcome }\end{array}$ & $\begin{array}{r}\text { Original (and } \\
\text { reverse) coding } \\
\text { Logit link }\end{array}$ & $\begin{array}{r}\text { Original coding } \\
\text { Comp. log-log } \\
\text { link }\end{array}$ & $\begin{array}{r}\mathbf{B} \\
\text { Reverse coding } \\
\text { Comp. log-log } \\
\text { link }\end{array}$ & $\begin{array}{r}|\mathbf{C}-\mathbf{C}| \\
\text { Palindromic } \\
\text { invariance }\end{array}$ \\
\hline$R_{\mathrm{M}}^{2}$ & 1 & $.3808(.0218)$ & $.3662(.0232)$ & $.3662(.0232)$ & 0.0000 \\
& 2 & $.3846(.0218)$ & $.3662(.0234)$ & $.3672(.0233)$ & 0.0010 \\
& 3 & $.3602(.0219)$ & $.3432(.0231)$ & $.3468(.0227)$ & 0.0036 \\
$R_{\mathrm{CS}}^{2}$ & 4 & $.3734(.0242)$ & $.3625(.0245)$ & $.3571(.0255)$ & 0.0054 \\
& 1 & $.6721(.0231)$ & $.6536(.0257)$ & $.6536(.0257)$ & 0.0000 \\
& 2 & $.6616(.0230)$ & $.6435(.0257)$ & $.6445(.0255)$ & 0.0010 \\
& 3 & $.6256(.0241)$ & $.6078(.0262)$ & $.6116(.0255)$ & 0.0038 \\
$R_{\mathrm{N}}^{2}$ & 4 & $.5679(.0272)$ & $.5574(.0277)$ & $.5517(.0289)$ & 0.0057 \\
& 1 & $.7099(.0236)$ & $.6904(.0264)$ & $.6904(.0264)$ & 0.0000 \\
& 2 & $.7035(.0235)$ & $.6842(.0264)$ & $.6853(.0262)$ & 0.0011 \\
& 3 & $.6691(.0249)$ & $.6501(.0273)$ & $.6542(.0265)$ & 0.0041 \\
& 4 & $.6348(.0279)$ & $.6229(.0287)$ & $.6167(.0301)$ & 0.0062 \\
& 1 & $.3228(.0220)$ & $.2367(.0187)$ & $.2367(.0187)$ & 0.0000 \\
& 2 & $.3192(.0224)$ & $.2335(.0191)$ & $.2371(.0190)$ & 0.0036 \\
& 3 & $.2910(.0206)$ & $.2138(.0174)$ & $.2167(.0173)$ & 0.0029 \\
& 4 & $.2885(.0248)$ & $.2211(.0201)$ & $.2140(.0205)$ & 0.0071 \\
\hline
\end{tabular}

Note: $\quad R_{\mathrm{M}}^{2}$ is McFadden's (1974) coefficient, $R_{\mathrm{cS}}^{2}$ is Cox and Snell's (1989) coefficient, $R_{\mathrm{N}}^{2}$ is Nagelkerke's (1991) coefficient; the $D^{\prime}$ coefficient was developed by Smith et al. (2017); mean values based on 10,000 replicated samples; palindromic invariance is indexed by the absolute difference between coefficient values for models fitted with originally-coded and reverse-coded data, for the complementary log-log link function; see Figure 1 for distribution conditions 1, 2, 3, and 4

Provided in Table 6 is a portion of results obtained from ordinal regression model fitted to the simulated data. When results for the originally-coded and 
reverse-coded outcome are compared for ordinal models fitted using the asymmetric (negative log-log) link function, very little difference in the obtained coefficients of determination/discrimination values were observed-that is, palindromic invariance was evident for each of the indices. No difference in values of the indices occurred, of course, for the symmetric (logit) link function.

\section{Conclusion}

Ordinal regression is an important analysis technique for social science researchers. Although most applications of this regression technique in the literature choose a logistic link function, it is important to realize that other link function choices are available. The aim of this study was to examine alternative link function choices with ordinal regression models fitted to an extant data set, and also with simulated data. Issues of distributional appropriateness, link specificity, and palindromic invariance were examined via an exemplar analysis employing the Pew Research Center's Web Omnibus Survey data. Simulated data were used to compare the relative palindromic invariance (i.e., with small differences indicative of greater invariance) of four distinct indices of determination/discrimination, including Smith et al. (2017) proposed $D^{\prime}$ index, which, comparatively to the pseudo $R^{2}$ indices, showed the least palindromic invariance. Although this study specifically examined conditions of skewness, which the literature (e.g., Norusis, 2012) suggests being most critical when choosing a link function, future research might examine how varying levels of kurtosis or even higher-order moments might affect resultant coefficient of determination values or properties of palindromic invariance. Additional studies of interest might examine (1) how ordinary least squares (OLS) regression models perform relative to ordinal models when they are applied to discrete, ordinal outcomes, and (2) the conditions under which the results of the two approaches differ (e.g., variations in the number of discrete categories present in the outcome).

\section{Acknowledgements}

An earlier version of this paper was presented at the 2016 Mid-Western Educational Research Association Annual Meeting and Conference, Evanston, IL. 


\section{AN EXPLORATION OF LINK FUNCTIONS}

\section{References}

Box, G. E. P., \& Tidwell, P. W. (1962). Transformation of the independent variables. Technometrics 4(4), 531-550. doi: 10.1080/00401706.1962.10490038

Cole, M. J., \& McDonald, J. W. (1989). Bootstrap goodness-of-link testing in generalized linear models. In A. Decarli, B. J. Francis, R. Gilchrist, \& G.U.H. Seeber (Eds.), Statistical modelling (pp. 84-94). New York: Springer-Verlag. doi: 10.1007/978-1-4612-3680-1_10

Cox, D. R., \& Snell, E. J. (1989). The analysis of binary data ( $2^{\text {nd }}$ edition). London: Chapman and Hall.

Hilbe, J. (2009). Logistic regression models. Boca Raton, FL: Taylor and Francis. doi: 10.1201/9781420075779

Johnson, V. E., \& Albert, J. H. (1999). Ordinal data modeling. New York: Springer-Verlag. doi: 10.1007/b98832

Koenker, R. (2006). Parametric links for binary response. R News, 6(4), 3234. Retrieved from https://cran.r-project.org/doc/Rnews/Rnews_2006-4.pdf

McCullagh, P. (1978). A class of parametric models for the analysis of square contingency tables with ordered categories. Biometrika, 65(2), 413-415. doi: 10.1093/biomet/65.2.413

McCullagh, P. (1980). Regression models for ordinal data (with discussion). Journal of the Royal Statistical Society: Series B (Methodological), 42(2), 109142. doi: 10.1111/j.2517-6161.1980.tb01109.x

McFadden, D. (1974). Conditional logit analysis of qualitative choice behavior. In P. Zarembka (Ed.), Frontiers in econometrics (pp. 104-142). New York: Academic Press.

Nagelkerke, N. (1991). A note on a general definition of the coefficient of determination. Biometrika, 78(3), 691-692. doi: 10.1093/biomet/78.3.691

Norusis, J. M. (2012). IBM SPSS statistics 19.0 advanced statistical procedures companion. Upper Saddle River, NJ: Prentice Hall.

Pew Research Center. (2014). 25th anniversary of the web omnibus survey. Retrieved from https://www.pewinternet.org/datasets/january-2014-25thanniversary-of-the-web-omnibus/

Pregibon, D. (1980). Goodness of link tests for generalized linear models. Applied Statistics, 29(1), 15-23. doi: 10.2307/2346405

Smith, T. J., Walker, D. A., \& McKenna, C. M. (2017, April). An examination of link function choice in ordinal regression models. Paper presented 


\section{SMITH ET AL}

at the annual meeting of the American Educational Research Association, San Antonio, TX.

Tjur, T. (2009). Coefficients of determination in logistic regression modelsA new proposal: The coefficient of discrimination. The American Statistician, 63(4), 366-372. doi: 10.1198/tast.2009.08210 